\title{
APRENDIZAGEM DE SEGUNDA LÍNGUA POR MEIO DA EDUCAÇÃO ONLINE ABERTA: \\ O USO DE TECNOLOGIAS DIGITAIS, GAMIFICAÇÃO E AUTODIDATISMO \\ NO PROCESSO DE AQUISIÇÃO LINGUÍSTICA
}

SECOND LANGUAGE LEARNING THROUGH OPEN ONLINE EDUCATION:

THE USE OF DIGITAL TECHNOLOGIES, GAMIFICATION AND AUTODIDACTICISM

IN THE PROCESS OF LINGUISTIC ACQUISITION

APRENDIZAJE DE SEGUNDA LENGUA POR MEDIO DE LA EDUCACIÓN ONLINE ABIERTA:

EL USO DE TECNOLOGÍAS DIGITALES, GAMIFICACIÓN Y AUTOAPRENDIZAJE

EN EL PROCESO DE ADQUISICIÓN LINGÜÍSTICA

Cláudio Ricardo Corrêa ${ }^{1}$

RESUMO

Este estudo aborda como ocorre o ensino/aprendizagem de segunda língua - por meio da educação online aberta - tendo como viés o uso de tecnologias digitais (em especial as de acesso à internet). Entre os temas abordados estão: gamificação, tecnologias de informação e comunicação (TICs), ambientes virtuais de aprendizagem (AVAs), educação a distância (EAD), cibercultura, autodidatismo, autonomia, pensamento crítico, autoria, inclusão e democratização do acesso à aprendizagem. Para isso optou-se pelos cursos, aplicativos e sites de ensino/aprendizagem de segunda língua gratuitos. Trata-se de uma pesquisa qualitativa para a qual foram selecionados participantes adultos - falantes nativos de língua portuguesa, que não tiveram instrução formal da língua-alvo -, que fizeram testes de nivelamento comparativos (iniciais e finais), com o propósito de averiguar a aprendizagem. O curso-base escolhido para os participantes foi o Duolingo. Também foram agregados outros meios digitais de educação aberta, disponíveis para prática, interação, aperfeiçoamento e desenvolvimento de competência linguística.

PALAVRAS-CHAVE: Autodidatismo. Ensino/aprendizagem de segunda língua. Ensino online aberto. Gamificação. Tecnologias digitais.

\section{ABSTRACT}

This study approaches how second language teaching/learning occurs - in open online education - by making use of digital technologies (specially those with internet access). Among the topics covered are: gamification, information and communication technologies (ICTs), virtual learning environments (VLEs), distance education, cyberculture, self-learning, autonomy, critical thinking, authorship, inclusion and democratization of access to

Submetido em: 20/09/2020 - Aceito em: 14/12/2020- Publicado em: 24/12/2020

\footnotetext{
${ }^{1}$ Doutorando em Letras (Estudos de Língua - Linguística) pela UERJ.

E-mail: correadtp@gmail.com. Lattes: http://lattes.cnpq.br/3796199498443886
} 
learning. In order to do that, free courses, applications and second language teaching/learning sites were chosen. This is a qualitative research in which adult participants - native speakers of Portuguese language, who did not have formal instruction in the target language - were selected and did comparative (initial and final) placement tests tests, with the purpose of ascertaining learning. The basic course chosen for the participants was Duolingo. Other digital sources of open online education, available for practice, interaction, improvement and development of linguistic competence, were also added.

KEYWORDS: Autodidacticism. Second language teaching/learning. Open online education. Gamification. Digital technologies.

\section{RESUMEN}

Este estudio aborda cómo se produce la enseñanza/aprendizaje de una segunda lengua - por medio de la educación online abierta - teniendo como eje el uso de tecnologías digitales (especialmente las de acceso a Internet). Entre los temas tratados, se encuentran: gamificación, tecnologías de la información y comunicación (TIC), ambientes virtuales de aprendizaje (AVA), educación a distancia (EAD), cibercultura, autoaprendizaje, autonomía, pensamiento crítico, autoría, inclusión y democratización del acceso al aprendizaje. Para ello, optamos por cursos gratuitos, aplicaciones y sitios de enseñanza/aprendizaje de segundas lenguas. Se trata de una investigación cualitativa, en la que se seleccionaron participantes adultos - hablantes nativos de lengua portuguesa, que no tuvieron instrucción formal en la lengua - meta - que realizaron pruebas de nivelación (iniciales y finales), con el propósito de conocer su aprendizaje. Se eligió como curso base a los participantes la aplicación Duolingo. También se agregaron otros medios digitales de educación abierta, disponibles para la práctica, interacción, mejora y desarrollo de la competencia lingüística.

PALABRAS CLAVE: Autoaprendizaje. Enseñanza/aprendizaje de una segunda lengua. Enseñanza abierta en línea (ou online) Gamificación. Tecnologías digitales.

\section{INTRODUÇÃO (FASE PRELIMINAR)}

A pesquisa está centrada no ensino/aprendizagem de segunda língua (L2), por meio da educação online aberta e tendo como viés o uso de tecnologias digitais, mas sem desvinculá-la de uma preocupação social. Ao longo da dissertação foram abordados o ensino/aprendizagem de L2; tecnologias digitais (em especial as de acesso à internet); TICs, EAD, educação online (e-learning); autonomia, independência; interdependência; autossuficiência; autodidatismo; flexibilidade; recursos adicionais de educação online aberta; jogos digitais; gamificação; estratégias de aprendizagem; motivação... $\mathrm{Na}$ estruturação do texto, optou-se por uma associação entre a nomenclatura do gênero dissertação e as fases de um jogo digital. Assim sendo, os capítulos foram considerados como fases de um jogo.

Como objetivo geral procura-se responder se é possível aprender uma L2 e com isso se dá. Já os objetivos específicos são contemplados por meio de um estudo qualitativo longitudinal sobre o curso/aplicativo Duolingo - que se propõe a ensinar línguas utilizando características 
de gamificação - e por um levantamento investigativo com autodidatas que aprenderam outras línguas por conta própria, exercendo processos de aprendizagem autônoma e fazendo uso de tecnologias digitais.

$\mathrm{Na}$ Introdução (Fase preliminar), o leitor é situado em relação à motivação, de onde nasceu a vontade de pesquisar esse tema; delimitação do problema; justificativa; objetivos geral e específico e estrutura do trabalho. No capítulo Revisão da literatura (Fase 1) é apresentada a fundamentação teórica (estratégias de aprendizagem; métodos/abordagens; tecnologias digitais; gamificação; autodidatismo e autonomia) e é feita uma descrição do curso-base utilizado pelos participantes da pesquisa. No capítulo Abordagem metodológica (Fase 2) faz-se uma descrição da metodologia da pesquisa utilizada neste estudo qualitativo; delimitação do corpus; critérios de seleção; o contexto da pesquisa; os participantes (Grupos A e B); os instrumentos, técnicas e procedimentos de coleta/geração de dados (entrevistas, formulários, testes de nivelamento e progresso, diários de bordo); critérios das análises dos dados. No capítulo Apresentação e discussão dos dados (Fase 3) são divulgados os dados gerados ao longo da pesquisa, assim como discussões, análises e considerações sobre o Duolingo e acerca dos dados dos participantes dos Grupos A e B. Na Conclusão (Game over) são feitas as considerações finais em relação às perguntas norteadoras da pesquisa. Conta-se ainda com Referências e Apêndices.

\section{REVISÃO DA LITERATURA (FASE 1)}

Buscar alternativas ao ensino tradicional e incluir as tecnologias digitais na educação são grandes desafios. Lembrando que não se trata apenas de uma questão de suporte. Segundo Cardoso (2015), os pedagogos têm que estar conscientes de seu papel e serem capazes de empregar os novos recursos tecnológicos digitais para melhorar a aprendizagem. "Enquanto a escola continua linear, mecânica, reducionista, o mundo está cada dia mais complexo, aberto, interdisciplinar, colaborativo, e hipertextual." (Idem, ibidem, p. 2.700).

Santos (2010, p. 37-38), ao definir a educação online como "o conjunto de ações de ensino e aprendizagem ou atos de currículo mediado por interfaces digitais que potencializam práticas comunicacionais interativas e hipertextuais", deixa claro que essas ações potencializam a democratização da informação, da comunicação e da aprendizagem entre indivíduos geograficamente dispersos.

Durante a revisão de literatura faz-se uma descrição do curso-base (Duolingo) que é utilizado pelos participantes da pesquisa. O Duolingo adota a estratégia de gamificação - entendida aqui na mesma perspectiva que Kapp (2012) como "a utilização de mecânica, estética e 
pensamento baseados em games para engajar pessoas, motivar a ação, promover a aprendizagem e resolver problemas".

Nas seções deste capítulo/fase são apresentados ainda os referenciais teóricos sobre estratégias de aprendizagem (Cardoso, 2005, 2015; O’Malley e Chamot, 1990; Oxford, 1990; Pozo, 1996, Tarone, 1981); educação online (Kenski, 2013; Santos, 2010; Silva, 2000); tecnologias digitais (Miranda, 2007; Sancho, 2010); gamificação (Kapp, 2012; Leffa, 1998, 2003; McGonigal, 2012; Rego, 2015; Salen e Zimmerman, 2004; Werbach e Hunter, 2012); autodidatismo (Demo, 2011, 2013); e autonomia (Allwright, 1990; Cardoso, 2005, 2015; Cimino; 2007; Demo, 2008, 2009; Freire, 1996; Scharle e Szabó, 2000).

\section{ABORDAGEM METODOLÓGICA (FASE 2)}

A pesquisa foi feita por meio de um estudo qualitativo. Para esse fim, foi feito um recorte que tem dois pontos principais em sua linha de investigação.

PRIMEIRO: foi feito um estudo longitudinal, com os participantes do Grupo A, cujo objetivo era averiguar a aprendizagem de L2 por meio do Duolingo e de outros recursos gratuitos disponíveis na educação online aberta. A mensuração se deu em dois momentos por meio de testes no padrão CEFR - antes e depois de cursarem o Duolingo e da concomitante utilização dos demais recursos. As questões que conduziram esta parte da pesquisa foram estas: $E$ possível aprender uma segunda língua por meio do Duolingo e quanto se aprende? Como a gamificação no ensino de línguas é utilizada por esse curso? Como as tecnologias digitais contribuíram para isso? Quais recursos adicionais foram utilizados?

SEGUNDO: foi feito um levantamento investigativo a partir de entrevistas com os participantes do Grupo B, os quais aprenderam outras línguas por conta própria, exercendo processos de aprendizagem autônoma e também fazendo uso de tecnologias digitais. Para isso a questão norteadora foi agrupada assim: Como, quais as estratégias e quais tecnologias digitais os autodidatas utilizaram para aprender uma segunda língua?

A Figura 1 condensa as etapas da pesquisa que deram origem a esta dissertação.

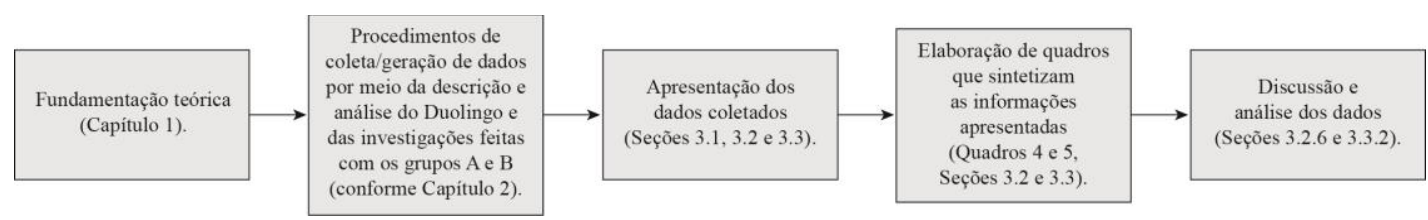


Figura 1. Etapas da pesquisa.

Fonte: o autor.

\section{APRESENTAÇÃO E DISCUSSÃO DOS DADOS (FASE 3)}

O capítulo começa com a análise e as considerações sobre o curso-base escolhido para essa pesquisa, de modo a se diagnosticar suas principais características. Logo após o cadastramento, que é bem simples - bastando um e-mail válido e uma senha -, percebe-se alguns padrões de interação, com fácil reconhecimento da interface que prima pelo alto grau do que se costuma chamar de affordance ${ }^{2}$ - um traço muito comum aos jogos digitais. Posteriormente às devidas configurações básicas de definição da quantidade de lições que serão feitas por dia - de acordo com a disponibilidade do aprendiz -, podem ser estabelecidos tempos médios (de 5, 10, 20, 30... minutos) nos quais se fará uma ou mais lições. Isso vai nortear o ritmo dos estudos diários. Sendo a participação diária uma das peculiaridades do Duolingo.

Ao se olhar pela primeira vez a estrutura do Duolingo, nota-se a árvore (mapa) composta de unidades e lições. O estudante consegue ver um começo, meio e fim. Isso acaba por demonstrar que há um planejamento a ser seguido. Sabe-se desde o início aonde se vai chegar (ao final há uma corujinha sobre um pódio). A mecânica de jogo adotada pelo Duolingo deixa claro, de modo leve e intuitivo, como funciona, por onde se inicia e para onde se vai.

Na primeira tela que aparece ao entrarmos no site/aplicativo, vê-se uma unidade colorida e todas as demais em cinza. Só se pode começar por ali, pela colorida, as demais estão bloqueadas. Isso é perceptível visualmente. O curso quer que o estudante inicie sua jornada pela porta de entrada que ele definiu. O início tem um grau de dificuldade bem baixo o que leva o aprendiz a acertar e ganhar confiança e motivação, mexendo com seu lado emocional de maneira positiva. E mesmo que se erre, há um feedback simples explicando que a resposta estava errada e uma nova oportunidade lhe é dada.

A tradução entre a língua-alvo (a que se quer aprender) e a língua-base (a que se utiliza para aprender) ou vice-versa, bem como a repetição e o reforço para fixação, são as características

\footnotetext{
${ }^{2}$ Affordance é um termo criado por James Jerome Gibson - psicólogo americano, que muito contribuiu no campo da percepção visual - e que pode ser explicado de maneira simplificada como o potencial de um objeto de ser usado como foi projetado para tal. É a qualidade de um objeto que permite a identificação de sua funcionalidade sem a necessidade de explicação prévia, o que ocorre intuitivamente ou baseado em experiências comuns (por exemplo, uma maçaneta, os ícones de um programa de computador, placas indicativas, botões de ligar e desligar etc., que nos remetem ao universo cotidiano, revelando sua função). Quanto maior for a affordance de um objeto, melhor será a identificação de seu uso.
} 
preponderantes da metodologia utilizada. Os idealizadores do Duolingo optaram por criar uma estrutura que pudesse ser funcional e viável, tanto do ponto de vista da gamificação quanto do ensino de línguas, além, é claro, de manter baixos os custos operacionais. Conseguiram fazer uso das tecnologias digitais disponíveis com relativo êxito, já que o número de usuários não para de crescer e pela satisfação dos usuários. Avaliar a eficácia e qualidade da aprendizagem é um dos interesses desta pesquisa.

\section{Discussão dos dados do Grupo A}

QUESTÃO NORTEADORA 1: É possível aprender uma segunda língua por meio do Duolingo e quanto se aprende? No que se refere à primeira questão, a resposta é um "sim com ressalvas", pois os números demonstraram que houve aprendizagem, mas esta foi parcial e com ênfase nos aspectos lexicais e sintáticos, sem avanços significativos quanto à capacidade comunicativa, pelo menos neste curto período de tempo de duração da pesquisa e de acordo com a amostragem deste estudo qualitativo. Deve-se salientar, também, que apesar de ter havido aprendizagem, esta difere da preconizada por Freire (1996) e Demo (2013) e com a qual este pesquisador concorda, pois a metodologia adotada não colabora para a produção ou construção própria e nem gera pensamento crítico. Há que se destacar que o Duolingo faz bom uso de tecnologias digitais (principalmente de dispositivos móveis com acesso a internet) e de características de gamificação. Por isso considerou-se outros pontos, também investigados, e que podem contribuir para superar as limitações encontradas.

QUESTÃO NORTEADORA 2: Como a gamificação no ensino de línguas é utilizada por esse curso? Neste aspecto, as contribuições foram mais efetivas e várias das características de gamificação acabaram sendo utilizadas de maneira positiva (SALEN e ZIMMERMAN, 2004; KAPP, 2012; REGO, 2015). Os participantes elogiaram o feedback imediato (que gerava motivação, noção de importância, correção positiva); a superação de metas (como fios condutores, que mantinham os aprendizes dispostos a vencer desafios intermediários e que serviam de ponte para a meta final, a obrigatoriedade de cursar o Duolingo diariamente, gerando disciplina e regularidade); a mecânica de jogo e os níveis de progressão (que mostravam as regras levemente, quase de maneira intuitiva, o estilo passo a passo, etapas com dificuldades gradativas, exigências que iam aumentando aos poucos, as vitórias que levavam a novos níveis, desbloqueios de seções); a estética (a boa utilização de cores, gráficos, imagens que auxiliavam na compreensão e resolução das lições); a aprendizagem colaborativa (que se não chegou a ser exercida de maneira contundente, pelo menos foi apresentada e percebida, pois os participantes tinham a quem recorrer nos fóruns e dentro do grupo); os prêmios e recompensas (a conquista de lingotes para comprar benefícios, fazer apostas, os brasões e títulos, a valorização da performance, o prazer de vencer desafios); a motivação, a competição e a cooperação (foi destacada a competição sadia e sua 
característica intrínseca de fator motivacional, mas em relação à cooperação esta se manifestou por meio dos fóruns com a mesma limitação percebida na aprendizagem colaborativa).

QUESTÃO NORTEADORA 3: Como as tecnologias digitais contribuíram para isso? A contribuição das tecnologias digitais foi marcante, tanto para fazer o curso-base quanto para utilizar outros recursos adicionais, principalmente em dispositivos móveis, que foram elogiados por todos os participantes, tendo em vista que facilitaram o acesso à educação online. E essa mobilidade, conjugada com o acesso a internet, ampliou as oportunidades, na medida em que possibilitou o estudo, a prática e o aperfeiçoamento dos participantes do Grupo A. Além disso, foi possível interagir com outros membros do grupo, mesmo estando em pontos distintos (SANTOS, 2010).

QUESTÃO NORTEADORA 4: Quais recursos adicionais foram utilizados? Além de cursar o Duolingo, os participantes utilizaram aplicativos para celulares; assistiram vídeos no YouTube, séries e filmes (com e sem legendas); cursaram MOOCs; utilizaram Google tradutor; leram e ouviram livros infanto-juvenis, assistiram desenhos animados, clipes musicais, entrevistas, etc. No entanto, apesar desses vários recursos terem sido utilizados, esperava-se um uso mais sistemático por parte do Grupo de A - mesmo diante de tanta oferta, o uso efetivo ficou um pouco abaixo do estimado.

\section{Discussão dos dados do Grupo B}

QUESTÃO NORTEADORA AGRUPADA: Como, quais as estratégias e quais tecnologias digitais os autodidatas utilizaram para aprender uma segunda língua? Os participantes do Grupo B, e que colaboraram com este levantamento investigativo, foram quase unânimes em destacar organização, dedicação, disciplina e regularidade como fatores primordiais para a aprendizagem de L2. É o próprio aprendiz quem precisa planejar o modo de estudar e essas características são ferramentas imprescindíveis para que esse planejamento funcione, associados, é claro, a um pensamento crítico, autoquestionamento e iniciativa.

Algumas estratégias e materiais de apoio (que serviram de base para a aprendizagem) foram mencionados, entre eles, a multiplicidade de mídias; a leitura de livros, jornais e textos na L2; uso de tradutores, dicionários e gramáticas online, aplicativos de conversas e interações; assistir a vídeos e ouvir áudios na internet; filmes e séries com e sem legendas; livros com metodologias de autoaprendizagem e até mesmo o Duolingo foi lembrado. Eles perceberam que precisavam ser responsáveis por suas atitudes a ponto de tomarem às rédeas e monitorarem seus próprios itinerários, aproveitando cada oportunidade de aprender. 
Não se conformaram com o que a escola tradicional regular não lhes ofereceu e nem se intimidaram com a escassez de verba, conseguiram encontrar entre as metodologias disponíveis e acessíveis, livros (coleções), sites, aplicativos, DVDs, estudo regular, enfim, utilizando material adequado. E para isso foi fundamental deixar de lado a postura de aguardar que lhe digam $o$ quê e como fazer. O fato de incluírem leitura, vídeos, áudios, interações interpessoais, revisões, estudo gramatical, fixação de vocabulário, uso de aplicativos, de dicionários online, etc. como modos regulares de estudo, denotam o uso diversificado e combinado a fim de fomentar a competência linguística.

E quanto às tecnologias digitais, os participantes do Grupo B informaram que estas foram de extrema importância, pois possibilitaram o acesso aos recursos utilizados, promovendo interações de cooperação, facilitando o aperfeiçoamento e os processos de compreensão da língua, permitindo o uso de aplicativos em dispositivos móveis, bem como as demais tecnologias já citadas. O que eles fizeram foi escolher de maneira criteriosa as TICs de modo a potencializar as condutas interativas e de comunicação entre sujeitos distantes fisicamente.

Reconhecemos que a amostragem é pequena, mas com os dados levantados no Grupo B, encontraram-se indícios de que a premissa levantada - de melhoria da competência linguística - poderia gerar efetivamente boas condições para compensar a limitação da capacidade de comunicação, identificada a partir dos dados coletados no Grupo A.

\section{CONCLUSÃO (GAME OVER)}

Conforme foi possível ver ao longo desta pesquisa, a ampliação do acesso às tecnologias digitais não garante por si só os resultados. Percebeu-se que ainda não existe uma pedagogia específica consagrada ou que sirva de modelo. São pedagogias em construção, que vão emergindo em meio às novas descobertas, adaptadas às condições tecnológicas e recursos disponíveis em um mundo globalizado e com realidades bem distintas.

Faz-se necessário que fiquemos atentos, pois precisamos tratar a língua não como um objetivo, mas como um meio de se alcançar um objetivo. Concordando com a opinião de Leffa (2016), não dá mais para continuar tratando o ensino de língua destituindo-a de suas funções essenciais que são comunicar, falar de nós, falar do mundo, agir sobre si e sobre o outro, expressar nossas ideias e pensamentos, informar, mostrar nossa perspectiva, ou seja, dar vazão à nossa voz.

Os participantes do Grupo A elogiaram o ganho lexical que tiveram, porém, constataram que ainda enfrentavam dificuldades para se comunicar de modo espontâneo. Por este pequeno 
conjunto de participantes e pelos fóruns e estrutura do próprio Duolingo - apesar de não se permitir uma generalização -, percebeu-se que adquirir vocabulário (com ênfase na tradução) despontou como uma forte característica da metodologia do curso. Contudo, se considerarmos os resultados do Grupo B, fazer o curso - associado a outras estratégias de aprendizagem regulares e conscientes - poderia levar os participantes a agilizar a conquista e o desempenho dessa e de outras competências.

A gamificação adotada pelo curso teve o mérito de manter os estudantes comprometidos e engajados em boa parte do tempo. E estudar é o melhor caminho para aprender. O que não se pode fazer é ficar esperando que as coisas caiam no nosso colo. E foi isso que os participantes do Grupo B demonstraram: que não há uma maneira única de aprender. Eles conseguiram ter autonomia para escolher as próprias estratégias de aprendizagem e não se restringiram a uma metodologia apenas.

Os autodidatas entrevistados utilizaram tecnologias digitais como uma das principais ferramentas para o aprimoramento da fluência em seus idiomas. E por meio dos recursos oferecidos pela internet, conseguiram driblar uma das principais dificuldades encontradas por muitos, a de não terem situações de comunicações autênticas no dia a dia. Mesmo sem tê-las, deram um jeito de encontrar mecanismos de compensação, fazendo uso de "ferramentas" digitais que ocuparam esse lugar vago. Se uma das características da educação a distância é a viabilização de contato entre pessoas espacialmente dispersas, pôde-se identificar em alguns dos participantes do Grupo B essa aproximação por meio de conversas online, mediadas por aplicativos muito comuns em dispositivos móveis e que, aos poucos, se tornam mais acessíveis financeiramente.

Estratégias de aprendizagem atingiram outro patamar de disponibilidade com as tecnologias digitais, com grande ênfase nas de acesso à internet. Aconselha-se, aos que forem optar por aprender ou aperfeiçoar uma L2 - por meio da educação online aberta -, que exerçam sua autonomia de escolha dos melhores caminhos, mas que também entendam a interdependência como uma coisa salutar.

No decorrer desta pesquisa, percebi que podemos aprender a aprender. E isso se faz, de modo mais produtivo, quando encontramos educadores generosos (por contato direto ou indireto), que dividem conosco suas experiências, nos ensinam a pensar por conta própria, desejosos de dar asas aos discípulos que - espera-se um dia - não apenas saibam voar sozinhos, mas que aprendam o seu próprio jeito de voar e voem mais alto do que eles próprios. 


\section{REFERÊNCIAS}

ALLWRIGHT, Dick. (1990). “Autonomy in language pedagogy.” Palestra apresentada na Sociedade Brasileira de Cultura Inglesa. RJ (apud Mitrano-Neto, 1994).

CARDOSO, Janaina da Silva. As estratégias de aprendizagem: eficácia e autonomia na compreensão oral. Tese de doutorado. Niterói: UFF, 2005.

CARDOSO, Janaina da Silva. Letramentos digitais e a formação de professores da geração conectada. Congresso Internacional da Abralin. In: LIMA, Larissa et al. (Org.). Anais do IX Congresso Internacional da Abralin. Belém: Abralin; PPG, UFPA, 2015. (v. 4. p. 2.6982.711)

CARDOSO, Janaina da Silva; BARBOZA, A.S.R.; COSTA, S.C.S.; LOPES,V.; SANTOS, S.D.; SANTIAGO, T.S.; SILVA, D.S.; SILVA, K.C. Estratégias de aprendizagem e tecnologias de informação e comunicação como facilitadores no processo de aprendizagem de idiomas. In: Linguagem: teoria, análise e aplicações (8). Organizadoras Angela Baalbaki, Janaina Cardoso, Poliana Arantes e Sandra Bernardo. Rio de Janeiro: UERJ, 2015. 615 p. (ISBN 978-85-64315-10-5).

CIMINO, Valdir. O papel do educador na era da interdependência. São Paulo: Clio, 2007.

DEMO, Pedro. EAD - Ensino a Distância. Autodidatismo: especialista dá dicas para estudar sem professor. Entrevista a Edgard Matsuki do UOL. Brasilia: 2013. Disponível em: $<$ https://educacao.uol.com.br/noticias/2013/01/14/autodidatismo-especialista-da-dicas-paraquem-quer-estudar-sem-professor.htm>. Acesso em: 12 ago. 2017.

DEMO, Pedro. Metodologia para quem quer aprender. São Paulo: Atlas, 2008a.

DEMO, Pedro. Pesquisa: princípio científico e educativo. São Paulo: Cortez, 2011.

DEMO, Pedro. Revista Brasileira de Docência, Ensino e Pesquisa em Educação Física, v. 1, n. 1, p.53-75, ago. 2009b. ISSN 2175-8093.

DUOLINGO (site). Disponível em <https://www.duolingo.com>. Todas as telas apresentadas na dissertação foram capturadas ao longo de 2017, de acordo com o andamento das atividades desenvolvidas pelos participantes da pesquisa. 
FREIRE, Paulo. Pedagogia da autonomia: saberes necessários à prática educativa. São Paulo: Paz e Terra, 1996.

KAPP, Karl, M. The Gamification of Learning and Instruction: game-based methods and strategies for training and education. São Francisco: Pfeiffer, 2012.

KENSKI, Vani Moreira. Tecnologias e tempo docente. Campinas: Papirus, 2013.

LEFFA, Vilson José. Metodologia do ensino de línguas. In: BOHN, H. I.; VANDRESEN, P. (Org.) Tópicos em linguística aplicada: o ensino de línguas estrangeiras. Florianópolis: Ed. da UFSC, 1988. p. 211-236. Disponível em: <http://www.leffa.pro.br/textos/trabalhos/Metodologia_ensino_linguas.pdf $>$. Acesso em 10 nov. 2017.

LEFFA, Vilson José. O ensino do inglês no futuro: da dicotomia para a convergência. In: STEVEnS, C. M. T.; CUNHA, M. J C. (Org.). Caminhos e colheita: ensino e pesquisa na área de inglês no Brasil. Brasília: Ed. da UnB, 2003. p. 225-250.

LEFFA, Vilson José. Redes sociais: ensinando línguas como antigamente. In: ARAÚJO, Júlio; LEFFA, Vilson (Org.). Redes sociais e ensino de línguas: o que temos de aprender. 1. ed. São Paulo: Parábola Editorial, 2016. p. 137-153.

LEFFA, Vilson José. Universidade Católica de Pelotas (UCPEL). In: SILVA, K. A.; ARAGÃO, R. C. (Org.). Conversas com formadores de professores de línguas: avanços e desafios. Campinas, SP: Pontes, 2013. p. 375-385.

McGONIGAL, Jane. A realidade em jogo. Rio de Janeiro: BestSeller, 2012.

O’MALLEY, J. Michael; CHAMOT, Anna Uhl. Learning strategies in second language acquisition. New York: CUP, 1990.

OXFORD, Rebecca. Language learning strategies. New York: Newbury House, 1990.

REGO, Izabel de Moraes Sarmento. Mobile Language Learning: How Gamification Improves the Experience. Campinas, SP: Unicamp, 2015. Disponível em: <https://www.researchgate.net/publication/303728892_Mobile_language_learning_How_ga mification_improves_the_experience>. Acesso em: dez. 2017.

ROJO, Roxane; MOURA, Eduardo. Multileramentos na escola. São Paulo: Parábola Editorial, 2012. 
SALEN, Katie; ZIMMERMAN, Eric. Rules of play: games design fundamentals. Cambridge: MIT Press, 2004.

SANCHO, Juana M. Para promover o debate sobre os ambientes virtuais de ensino e aprendizagem. In: SILVA, Marco; PESCE, Lucila; ZUIN, Antonio (Org.). Educação online: cenário, formação e questões didático-metodológicas. Rio de Janeiro: Wak Ed., 2010. p. 95106.

SANTOS, Edméa. Educação online para além da EAD: um fenômeno da cibercultura. In: SILVA, Marco; PESCE, Lucila; ZUIN, Antonio (Org.). Educação online: cenário, formação e questões didático-metodológicas. Rio de Janeiro: Wak Ed., 2010. p. 29-48.

SCHARLE, Ágota.; SZABÓ Anita. Learner autonomy: a guide to developing learner responsibility. Cambridge: Cambridge University Press, 2000.

SILVA, Marco. Sala de aula interativa. Rio de Janeiro: Quartet, 2000.

SILVA, Marco. Sala de aula interativa: a educação presencial e à distância em sintonia com a era digital e com a cidadania. In: INTERCOM - Sociedade Brasileira de Estudos Interdisciplinares da Comunicação. Anais do XXIV Congresso Brasileiro da Comunicação - A mídia impressa, o livro e o desafio das novas tecnologias, Campo Grande, MS, set. 2001.p. 1-20.

SILVA, Marco. Cibercultura e educação: a comunicação na sala de aula presencial e online. Revista FAMECOS. Porto Alegre, n. 37, p. 69-74, dez. 2008.

TARONE, Elaine. Some Thoughts on the Notion of Communication Strategy. TESOL Quarterly, v. 15, n. 3, p. 285-295Sep. 1981. Disponível em: <http://www.jstor.org/stable/ 3586754>. Acesso em: 14 dez. 2017.

WERBACH, Kevin; HUNTER, Dan. For the win: how game thinking can revolutionize your business. Philadelphia: Wharton Digital Press, 2012.

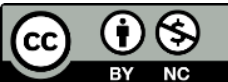

Este é um artigo de acesso aberto distribuído sob os termos da Licença Creative Commons Atribuição Não Comercial-Compartilha Igual (CC BYNC-4.0), que permite uso, distribuição e reprodução para fins não comerciais, com a citação dos autores e da fonte original e sob a mesma licença. 